Di Menna, M. E. (1957). J. gen. Microbiol. 17, 678-688

\title{
The Isolation of Yeasts from Soil
}

\author{
By MARGARET E. DI MENNA \\ Soil Bureau, Department of Scientific and Industrial Research, \\ Wellington, Nerw Zealand
}

\begin{abstract}
SUMMARY: A series of comparative studies was made of soil yeasts in a yellowbrown earth originally under forest but now under pasture. Of six solid acid media used for primary isolations, an agar medium containing $4 \%(w / v)$ glucose and $1 \%(w / v)$ peptone gave the highest yeast counts. Two soil-extract agars and a modified Czapek-Dox agar gave slightly lower counts; a third soil-extract agar inhibited all but one yeast species and gave a much decreased count. The addition of a surface active agent to glucose peptone agar did not increase the count. Acid broth enrichment cultures gave a distorted picture of the species pattern shown by primary cultures on solid media. Prolonged mechanical shaking of soil dilutions before culturing, and the addition of a surface active agent to the diluent did not affect the yeast pattern seen, quantitatively or qualitatively.
\end{abstract}

Past experience in the isolation of yeasts from mixed microbial populations (Marples \& di Menna, 1952; di Menna; 1945, 1955 $a, b, 1956$ ) has shown that a modified Sabouraud agar (glucose $4 \%(w / v)$, peptone $1 \%(w / v)$ ) brought to $\mathrm{pH} 4$ is a useful medium for primary cultures. All but acidophilic species of bacteria are inhibited and usually the only microbial interference is by spreading moulds. However, this medium may have several defects, particularly for the isolation of yeasts from soil. The relatively high concentration of nutrients may give rise to a variety of microbial interactions on isolation plates. The high acidity and the lack of growth factors present in some soil extracts may interfere with the development of some species. A series of parallel quantitative and qualitative surveys of the soil yeasts of one area was made in order to compare the effectiveness of Sabouraud agar with a number of other media, and to find the most suitable pre-cultural treatment of soil dilutions.

\section{METHODS}

The soil studied was Korokoro silt loam from Judgeford, near Wellington, New Zealand. It was classified as a moderately leached, moderately weathered, yellow-brown earth derived from greywacke (Taylor, 1948). The original vegetation was mixed broadleaf forest which had been burnt off about a hundred years ago and replaced with browntop-sweet vernal pasture. The natural fertility is medium to low. The site sampled was a moderately sloping hilltop at an elevation of about $1000 \mathrm{ft}$. above sea level. It had never been ploughed and was grazed by sheep. Chemical analysis of a sample of the 0-6 in. layer was as follows: $\mathrm{pH} 5.3 ; \mathrm{P}_{2} \mathrm{O}_{5}$ (1\% citric acid soluble), $0.007 \%$; total $\mathrm{N} \%, 0.34 ; \%$ base saturation, $36 ; \mathrm{C} / \mathrm{N}$ ratio, 16 .

Rainfall of 50-60 in. is evenly distributed throughout the year. The average annual temperature is about $54^{\circ} \mathrm{F}$. with a range of $46-61^{\circ}$. 
Sampling methods. Samples were taken at a depth of 4 in. by thrusting a sterile container into the side of a freshly dug pit. Usually one sample was taken from each of five pits spaced along a 100-yard transect, but in May 1955 one sample was taken from each of two opposing sides of five pits. The first sampling pit (sample 1) was always dug at the lower and wetter end of the slope. Forest dimples were avoided, pits being dug in areas of even slope. Collections of soil were made in May and October 1955, and in February, May, August and October 1956.

In addition, samples of pasture leaves were collected in May, August and October 1956 so that their yeast flora could be examined for control purposes. In May a single composite sample was taken; in August two samples were collected, one of grass leaves and one of clover leaves, and in October five samples were taken, one from directly above each of the five sample pits from which soils were collected. The leaves were clipped with sterile scissors into sterile containers. Care was taken to avoid gathering material splashed with soil or contaminated with earthworm castings, but when the pasture was closely grazed this was difficult.

Turves from each of the five sample pits dug in October 1956 were taken back to the laboratory so that grass roots could be dissected from them for culturing.

Cultivation methods. All soil samples and the washings from roots and leaves were cultured on plates of modified Sabouraud agar $(4 \%, \mathrm{w} / \mathrm{v}$, glucose; $1 \%$, w/v. peptone, British Drug Houses Ltd.; $2 \%$, w/v, Davis' New Zealand agar; referred to henceforth as $\mathrm{pH} 4$ glucose peptone agar) which had been brought to $\mathrm{pH} 4$ by the addition of $\mathrm{N}-\mathrm{HCl}$ to the molten medium immediately before pouring. The poured plates were dried for a short time in a warm oven so that the medium would absorb the moisture of the inoculum.

The soil dilution and culturing technique routinely used was as follows. Ten g. soil from each sample were weighed out with sterile precautions and made into serial dilutions of 1/250, 1/500 and 1/1000 with sterile tap water. The soil dilutions were shaken by hand for about 30 sec. as each dilution was made and were reshaken briefly before inocula were removed. An inoculum of $0.5 \mathrm{ml}$. was put on each $10 \mathrm{~cm}$. plate and spread with a glass spreader. Plates were incubated upside down at room temperature.

Leaf samples and roots dissected from turves were shaken with sterile tap water and the washings spread on $\mathrm{pH} 4$ glucose peptone agar plates. All samples were cultured as soon as possible after collection; any held overnight were kept in a refrigerator.

Cultures were incubated for 4-6 days before examination, the time varying with the season, the medium used, and the number of moulds appearing on the plates. Yeasts to be identified were picked systematically from the plates and subcultured into yeast extract glucose broth ( $\mathrm{pH} 4)$. The number of isolates . identified per sample per treatment varied from 10 to 50 .

Cultures were identified by the criteria of Lodder \& Kreger-van Rij (1952). Pullularia pullulans (De Bary \& Low) Berkhout was treated as a yeast. 
Parallel cultures. Five other solid media were tested against pH 4 glucose peptone agar. Three of these were soil-extract agars and two were media chosen particularly for their ability to decrease mould colony size. The first of these was the modified Czapek-Dox agar used by Neill \& Armstrong (1955) in their survey of blind seed disease, sucrose as the carbon source being replaced by Marmite. The second medium was glucose peptone agar to which had been added $0.01 \%$, w/v, Lubrol W (Imperial Chemical Industries Ltd.), a nonionic surface active agent which gives a neutral heat-stable solution.

The soil-extract agars were prepared by autoclaving one part of soil from the $\mathrm{A}$ horizon with three parts of tap water for $30 \mathrm{~min}$. at $15 \mathrm{lb} . / \mathrm{sq}$.in. $\left(121^{\circ}\right)$, filtering, diluting the filtrate by half with tap water, and adding sufficient agar to set. The three soils used were: Taita silt loam, a similar soil to Korokoro but developed under beech forest; Cass fine sandy loam, a strongly leached, weakly weathered, yellow-brown earth from greywacke alluvium; Waiwhetu silt loam, a recent soil from greywacke alluvium.

All these media were used at $\mathrm{pH} 4$ and were inoculated from the same soil dilutions as used for the cultures on $\mathrm{pH} 4$ glucose peptone agar.

Broth cultures. Some acid broth 'enrichment cultures' were made, rather so that results could be compared with those of other workers (Starkey \& Henrici, 1927; Capriotti, 1955) than because enrichment was necessary or desirable. Three acid broths were used: glucose yeast extract broth (Kurung, 1942), $1 \%$ peptone water, and carrot infusion. The broths were brought to $\mathrm{pH} \mathrm{4}$, dispensed in $90 \mathrm{ml}$. lots in $250 \mathrm{ml}$. Erlenmeyer flasks, and sterilized at $121^{\circ}$ for $15 \mathrm{~min}$. Ten g. soil from each sample examined were inoculated into a flask of each kind of broth and incubated at room temperature for a week, at the end of which time a heavy pellicle of moulds had formed. Samples of broth from beneath the pellicles were removed with Pasteur pipettes and plated out on $\mathrm{pH} 4$ glucose peptone agar. Recovery of ten yeasts/sample/treatment was attempted, but this was not always possible.

Pre-culturing treatments. Yeast colonies which developed on plates inoculated with soil suspensions may have arisen from single organisms or from aggregates. Skinner (1951) reported that by use of a shaking technique it was possible to determine whether actinomycetes in soils occurred predominantly as spores or as vegetative particles. It was hoped that the use of a similar shaking method would give information upon the state of yeasts in soil. Soil samples from the August 1956 collection were diluted serially with sterile tap water and cultured by the standard method on $\mathrm{pH} 4$ glucose peptone agar. The dilutions remaining after the inocula had been removed were then shaken for $15 \mathrm{~min}$. in a mechanical reciprocal shaker at 300 strokes/min. with an amplitude of 0.5 in. Cultures were then made from the mechanically-shaken dilutions. A parallel series of dilutions from the same collection were made in tap water containing $0.01 \%, \mathrm{w} / \mathrm{v}$, Lubrol $\mathrm{W}$ and were cultured in a similar manner, before and after $15 \mathrm{~min}$. mechanical shaking. 


\section{RESULTS}

On $\mathrm{pH} 4$ glucose peptone agar

There was very great site-to-site variation in numbers of soil yeasts. Counts from single samples varied between 6000 and 240,000 yeast colonies/g. soil. No seasonal trend in numbers was distinguishable. Four species, Cryptococcus albidus (Saito) Skinner, Cryptococcus terreus di Menna, Candida curvata (Diddens \& Lodder) Lodder \& van Rij and Schizoblastosporion starkeyihenricii Ciferri occurred in important numbers; very few strains of other species were recovered. Of these four species Cryptococcus terreus was the commonest in most collections. Schizoblastosporion starkeyi-henricii made up $75 \%$ of the isolates from the three higher and drier sites sampled in May 1955, but was represented in only small numbers in the five other soil collections. Detailed results are given in Table 1.

Yeasts on pasture leaves showed a seasonal change of species pattern (Table 2). In May (autumn) Sporobolomyces odorus Derx, Candida humicola (Daszewska) Diddens \& Lodder, and Schizoblastosporion starkeyi-henricii were isolated from the washings, but none of these species was present in the August and October (late winter and spring) collections, when Cryptococcus laurentii (Kafferath) Skinner and Torulopsis aeria (Saito) Lodder were dominant. The species pattern of yeasts in root washings was similar to that in soil samples collected at the same time.

\section{Comparative cultures on solid media}

Yeast counts on the three soil-extract agars were smaller than counts of the same samples cultured on $\mathrm{pH} 4$ glucose peptone agar (Table 3 ). The species pattern given by cultures on Taita and Cass soil-extract agars were similar to those given by $\mathrm{pH} 4$ glucose peptone agar, except that proportions of Cryptococcus terreus and Schizoblastosporion starkeyi-henricii were decreased a little. The count on Waiwhetu soil-extract agar was only a quarter of that on $\mathbf{p H} 4$ glucose peptone agar and Candida curvata was the only yeast recovered from the cultures.

Results from the two series of isolations made on Marmite + Czapek-Dox agar were similar to those made on the Cass and Taita soil-extract agars; counts were lower than on $\mathbf{p H} 4$ glucose peptone agar and the proportions of Cryptococcus terreus and Schizoblastosporion starkeyi-henricii were slightly diminished. The count on glucose peptone agar with Lubrol $W$ was only threequarters of that on $\mathrm{pH} 4$ glucose peptone agar without additions and no decrease in mould colony size was seen.

\section{Enrichment cultures in acid broths}

No yeasts were recovered from the carrot infusion cultures, spreading moulds completely covering the plates. Similarly, no yeasts were recovered from one of the soil samples incubated in glucose yeast extract broth; in other instances it was not possible to recover ten yeasts/sample/treatment. Candida humicola, 
Yeast colonies

(thousand)/g. soil

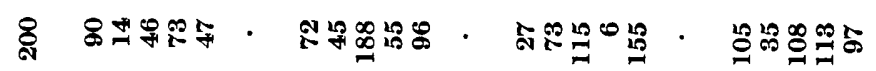

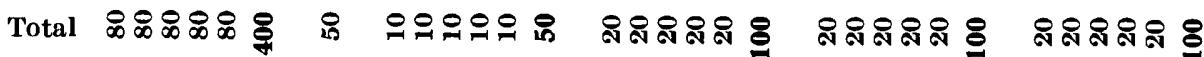

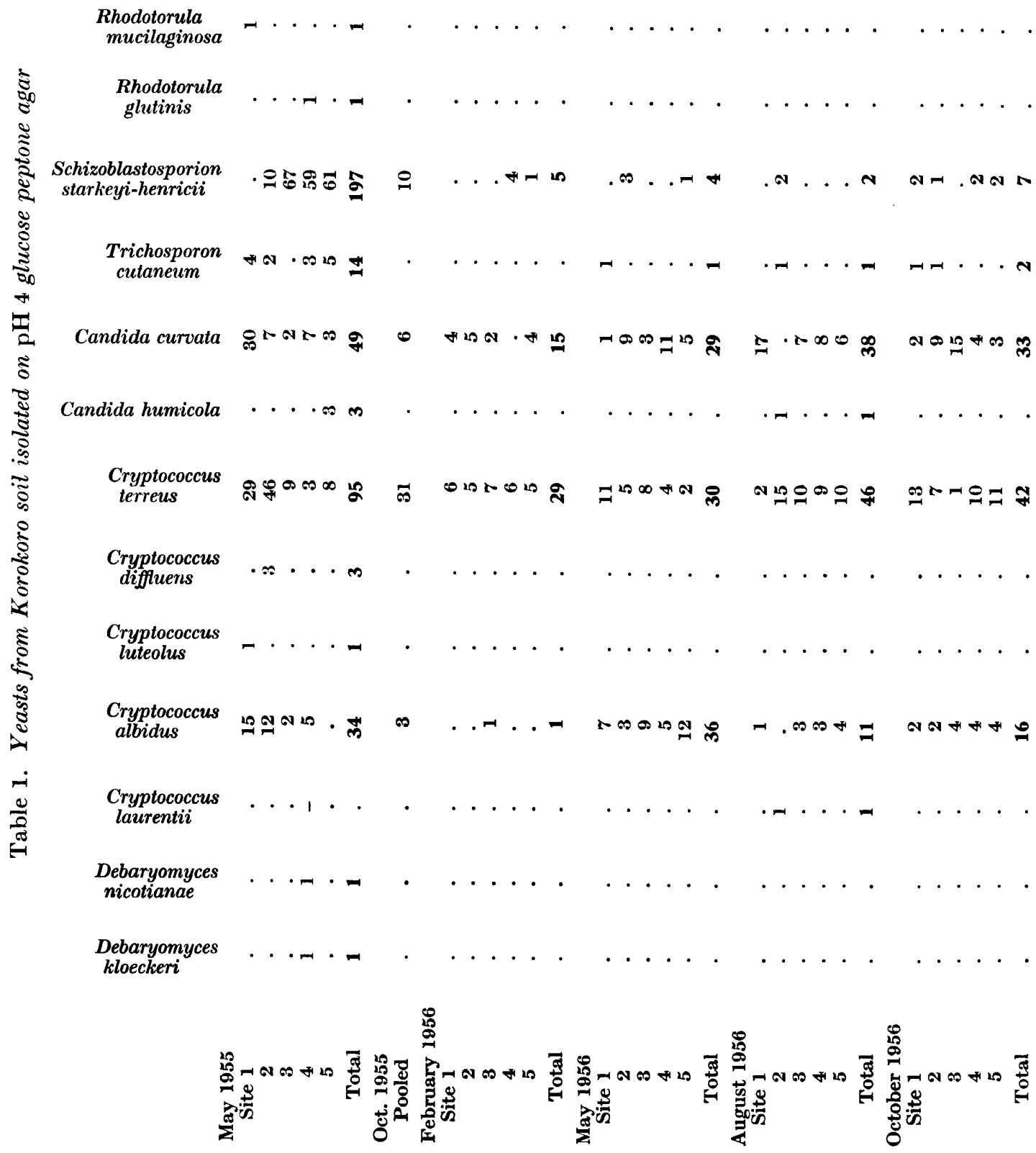




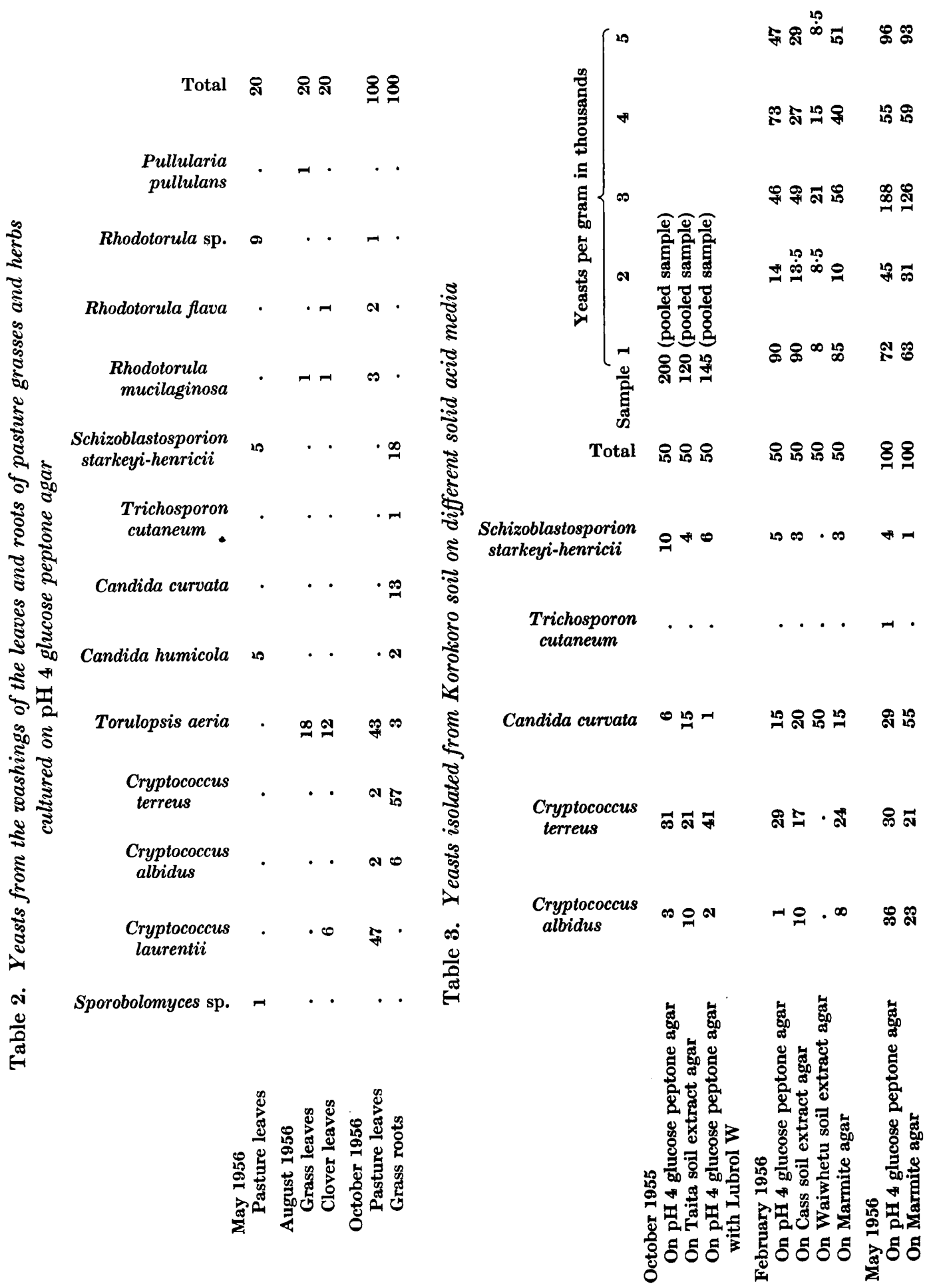



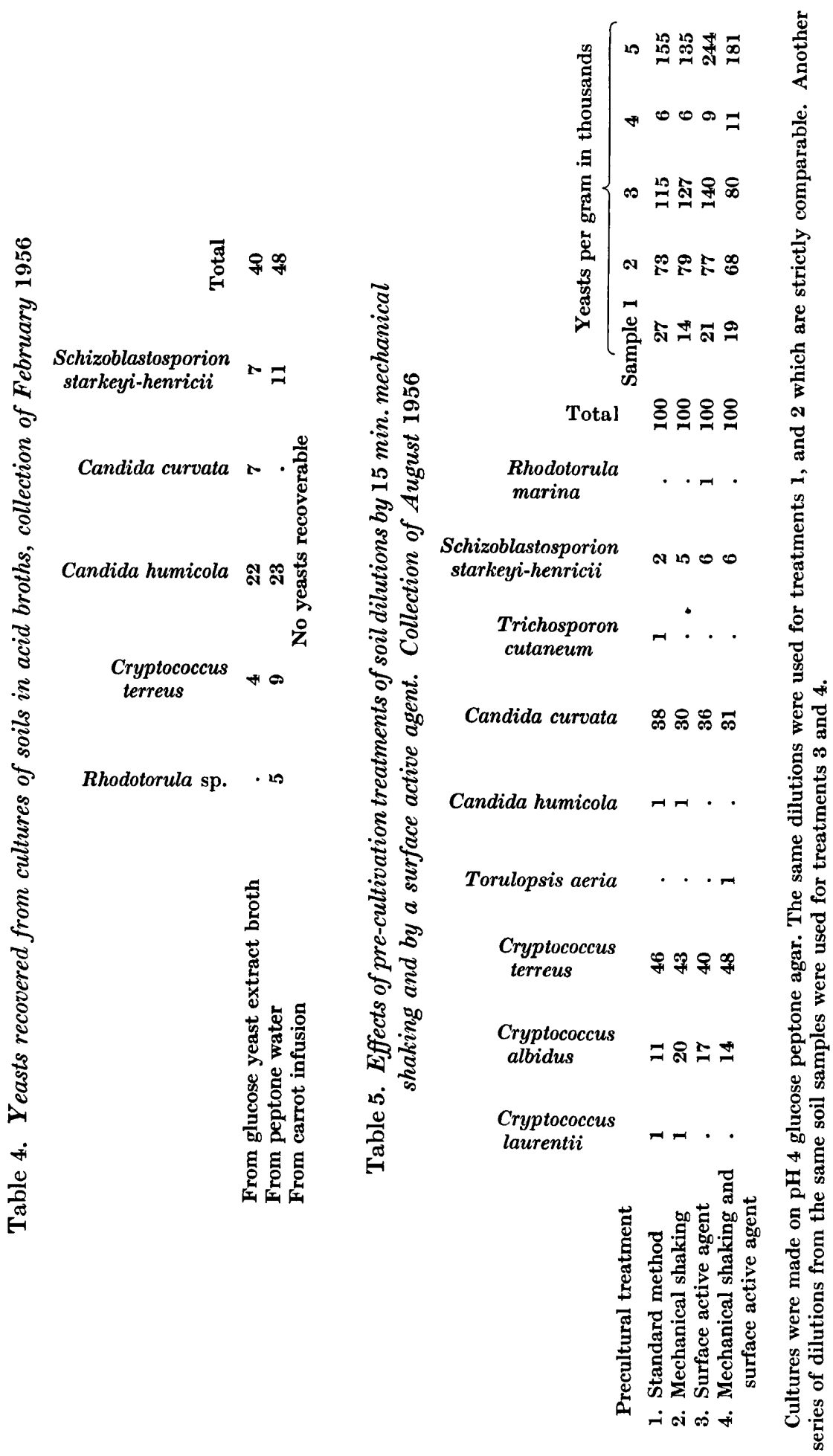
which was not isolated when the samples were cultivated on solid media, was the most common species in both the glucose yeast extract broth and the peptone water cultures. The results are given in Table 4.

\section{Pre-culturing treatments}

The counts obtained before and after $15 \mathrm{~min}$. shaking of soil dilutions in sterile water were similar. There was some decrease in counts after mechanical shaking in $0.01 \%, \mathrm{w} / \mathrm{v}$ Lubrol $\mathrm{W}$ in tap water, but this may have been experimental error rather than a real effect. Results are given in Table 5.

\section{DISCUSSION}

Of the six media used pH 4 glucose peptone agar consistently gave the highest yeast counts and so is most likely to reflect accurately the species pattern in soil. Any benefit from decrease in size of mould colonies by the use of starvation media such as Marmite + Czapek-Dox agar or soil-extract agars was more than offset by decreases in the numbers of yeast colonies which developed. The failure of a surface active agent to decrease mould colony size was probably due to the inoculum being spread on the surface of the medium and leaving a film of moisture. Unfortunately pour plates are not suitable for the isolation and enumeration of yeasts, for the colonies do not usually grow to the surface of the medium, which must therefore be dissected if they are to be subcultured. Also it is often necessary when counting to examine colonies with a low-power microscope objective in order to distinguish between yeasts and bacteria, and this is better done when the growth is on the surface.

Soil extract does not seem to be necessary for the growth of soil yeasts. Indeed the use of soil-extract agars appears to be a practice which can give misleading results. Results of surveys made using Cass and Taita soil-extract agars were very similar to those made using Marmite agar, which suggests that while these soil extracts did not stimulate soil yeasts and had a low nutrient value, they were able to support yeast growth tolerably. On the other hand, when Waiwhetu soil-extract was used the count was much decreased and only Candida curvata was recovered from the cultures. It is possible that the Waiwhetu soil extract contained a heat-stable antibiotic, or toxic material produced by autoclaving, to which Candida curvata was the only member of the yeast flora that was insensitive. Dobbs \& Hinson (1953) reported a fungistatic agent, widespread in soils, which may be removed by severe heating or prolonged desiccation, and the effect of which may be masked by the addition of glucose or other nutrients.

When $1 \%, w / v$, British Drug Houses Ltd. peptone and $0.5 \%$, w/v glucose were added to some of the original batch of Waiwhetu soil-extract agar, subcultures of strains of Rhodotorula sp., Cryptococcus albidus, Cryptococcus terreus, Candida curvata and Schizoblastosporion starkeyi-henricii, isolated from Korokoro soil and grasses, grew as well on it as on control cultures of $\mathrm{pH} 4$ glucose peptone agar without soil extract. The fungistatic agent of Dobbs \& Hinson (1953) may account for the properties of the Waiwhetu 
soil extract, although it would be necessary to presume that the same agent was lacking or in ineffective concentrations in the Cass and Taita soil extracts. It is still possible that a soil extract added to $\mathrm{pH} 4$ glucose peptone agar may foster the growth of some exacting species which would not appear on the more simple nutrient medium.

Broth enrichment cultures. These cultures, which yielded no information about yeast numbers in the soils, gave a distorted picture of the species pattern disclosed by cultures on solid media. Cryptococcus terreus and Candida curvata which were dominant in cultures on solid media were recovered from the broth cultures but in only minor proportions. They were replaced in order of frequency by Candida humicola, a species of which very few isolates have been recovered from Korokoro soil but which was common on grass leaves in the autumn. An acid broth which is rich in nutrients that are lacking or in very low concentrations in the soil, and which is overrun by zymogenous moulds, is a microcosm in which it is unlikely that yeasts suited for growth in the soil will flourish.

Pre-cultivation treatment of soil dilutions. Since mechanical shaking of soil dilutions, with or without the addition of a surface active agent, had no consistent effect upon the yeast count, it seems that naturally-occurring yeast colonies in the soil are either loosely held together and break apart when the soil is made into a slurry, or else are very stable and cannot be disturbed by prolonged agitation or alteration of the surface tension.

Relationship between yeast floras of phyllosphere and soil. With the exception of Schizoblastosporion starkeyi-henricii no yeast species occurred commonly both on leaves and in soil. Cryptococcus terreus was the most frequently occurring yeast in most soil sollections, although Cryptococcus albidus, Candida curvata and Schizoblastosporion starkeyi-henricii were all dominant on occasion. Site variation in species pattern was not usual in natural tussock grassland soils, neither under the original vegetation nor under introduced pasture (di Menna, unpublished), and variation in the Korokoro soil may indicate a micropopulation still transitional between forest and grassland types. Site variation in numbers in Korokoro soil was also much greater than in natural grassland soils and may possibly be related to the discontinuous effect of rotted forest remains in an unploughed soil. A seasonal change in numbers may have been obscured by the site variation, but it is also likely that no great seasonal fluctuation occurs in an area where the distribution of rainfall is even and the temperature range throughout the year is small.

Ruinen (1956) noted a limited and characteristic yeast flora on the phyllosphere of tropical plants, and Last (1955) observed seasonal variation in numbers of yeasts on the phyllosphere of cereal crops. Cryptococcus laurentii and Torulopsis aeria, which were the commonest isolates from washings of late winter and spring leaf samples, were not found on leaves taken in the autumn, and were isolated from the soil in very small numbers and only in the August and October collections. On the other hand, Schizoblastosporion starkeyihenricii, present on the pasture leaves in the autumn, was the predominant 


\section{Isolation of yeasts from soil}

yeast in the May 1955 soil collection and occurred consistently, although in small proportions, in all other soil collections. The ecological position of this species is difficult to determine; physiologically it differs from the yeasts which seem to be true soil inhabitants. $S$. starkeyi-henricii does not use nitrate nitrogen, is uncapsulated, and cannot synthesize growth factors or starch (di Menna, 1955a). It is tempting to suggest that it occurred in unusually large numbers on pasture leaves in the autumn of 1955, and that the large proportion of its colonies on plates inoculated with soil collected at that time had grown from inactive organisms washed into the soil. Nevertheless, it was able to maintain itself and was recovered regularly in small numbers from all soil collections, including those taken in the spring, when it did not occur on leaves. Also, Lund (1954) recovered it from European soils, and Starkey \& Henrici (1927) found one strain in a North American soil sample.

It seems desirable therefore, that an examination of the phyllosphere yeast flora be made in parallel with soil yeast studies, at least until more is known of the amount of interchange between the two floras, and particularly where the micropopulation may be in a disturbed state. At present a relatively rich, solid, acid medium appears to be best for the isolation of yeasts from soil. Although it encourages the growth of spreading moulds, it also stimulates yeast multiplication sufficiently to compensate for this.

My thanks are due to Mr L. C. Blakemore of the Soil Bureau for the chemical analysis of Korokoro soil, and to other colleagues in the Bureau for assistance in the selection of a sampling site. Soil Bureau Publication No. 119.

\section{REFERENCES}

CAPriotti, A. (1955). Yeasts in some Netherlands soils. Leeurvenhoek ned Tijdschr. $21,145$.

DobBs, C. G. \& Hinson, W. H. (1953). A widespread fungistasis in soils. Nature, Lond. 172, 197.

Kurung, J. M. (1942). The isolation and identification of pathogenic fungi from sputum. Amer. Rev. Tuberc. 46, 365.

LAST, F. T. (1955). Seasonal incidence of Sporobolomyces on cereal leaves. Trans. Brit. mycol. Soc. 38, 221.

Lodder, J. \& Kreger-van Ris, N. J. W. (1952). The Yeasts. A Taxonomic Study. Amsterdam: North Holland Publishing Co.

Lund, A. (1954). Studies on the Ecology of Yeasts. Copenhagen: Munksgaard.

Marples, M. J. \& Di Menna, M. E. (1952). The incidence of Candida albicans in Dunedin, New Zealand. J. Path. Bact. 64, 497.

MENNA, M. E. DI (1954). Non-pathogenic yeasts of the human skin and alimentary tract. J. Path. Bact. 68, 89.

MenNA, M. E. DI (1955a). A search for pathogenic species of yeasts in New Zealand soils. J. gen. Microbiol. 12, 54 .

MenNa, M. E. DI (1955b). A quantitative study of air-borne fungus spores in Dunedin, New Zealand. Trans. Brit. mycol. Soc. 38, 119.

MenNa, M. E. DI (1956). A search for Cryptococcus neoformans in milk. Leeurwenhoek ned Tijdschr. 22, 331.

Neill, J. C. \& Armstrong, C. S. (1955). An aerial survey of ascospore distribution of blind-seed disease of ryegrass (Gloeotinia (Phialea) temulenta). N.Z. J. Sci. Tech. A. 37, 106. 
Ruinen, J. (1956). Occurrence of Beijerinckia species in the 'phyllosphere'. Nature, Lond. 177, 220.

Skinner, F. A. (1951). A method for distinguishing between viable spores and mycelial fragments of Actinomycetes in soils. J. gen. Microbiol. 5, 159.

Starkey, R. L. \& Henrici, A. T. (1927). The occurrence of yeasts in soils. Soil Sci. 23, 33.

Taylor, N. H. (1948). Soil Map of New Zealand. N.Z. Soil Bur. Map. S.B. no. 280. 